\title{
Experimental Investigation on thermal comfort model between Local Thermal Sensation and Overall Thermal Sensation
}

\author{
Zhaosong Fang ${ }^{\mathrm{a} b \mathrm{c}}$, Hong Liu ${ }^{*} \mathrm{~b}$, Baizhan $\mathrm{Li}^{\mathrm{b} c}$, Meilan Tan ${ }^{\mathrm{d}}$, Oladokun Majeed Olaide \\ ( ${ }^{\text {a }}$ The School of Civil Engineering, Guangzhou University, Guangzhou 510006, P.R. China \\ ${ }^{b}$ The National Centre for International Research of Low-carbon and Green Buildings, Chongqing University, \\ Chongqing 400042, P.R. China \\ c Key Laboratory of the Three Gorges Reservoir Region's Eco-Environment (Ministry of Education), Chongqing \\ University, Chongqing 400042, P. R. China \\ ${ }^{\mathrm{d}}$ College of urban construction and safe engineering, Nanjing University of Technology, Nanjing 211800, P.R. \\ China \\ ${ }^{\mathrm{e}}$ Division of Building Science and Technology, City University of Hong Kong, Kowloon, Hong Kong) \\ * Corresponding author. Faculty of Urban Construction and Environmental Engineering, \\ Chongqing University, Chongqing 400045, PR China. Tel.: +86 2365127353; fax: +86 2365127815. \\ E-mail addresses: liuhong1865@163.com (H. Liu).
}

Abstract: To study human local and overall thermal sensations, a series of experiments under various conditions were carried out in a climate control chamber. The adopted analysis method considered the effect of the weight coefficient of local average skin temperature and density of the cold receptors' distribution in different local body areas. The results demonstrated that the thermal sensation of head, chest, back, and hands was warmer than overall thermal sensation. The mean thermal sensation votes of those local areas were more densely distributed. Also, the thermal sensation of arms, thigh, and calf was colder than the overall thermal sensation, which showed that thermal sensation votes were more dispersed. The thermal sensation of chest and back had a strong linear correlation with overall thermal sensation. Considering the actual scope of air-conditioning, the human body was classified into three local parts: a) head, b) upper part of body and c) lower part of the body. The prediction model of both the three-part thermal sensation and the overall thermal sensation was developed. Weight coefficients were $0.21,0.60$ and 0.19 respectively. The models provide basic installation guide of the personal ventilation system to achieve efficient energy use.

Keywords: Local thermal sensation; Overall thermal sensation; Weight coefficient; Prediction model; Thermal comfort

\begin{tabular}{|llll|}
\hline \multicolumn{2}{l}{ Nomenclature } & & \\
$P V$ & Personal ventilation & $\varepsilon g$ & globe emissivity \\
PMV & Predicted Mean Vote & $D$ & Globe diameter, mm \\
$M T S V / O T S$ & Mean thermal sensation vote & $T_{m r t}$ & Mean radiant temperature, ${ }^{\circ} \mathrm{C}$ \\
$T S V$ & Thermal sensation vote & $T_{o p}$ & Operative temperature, ${ }^{\circ} \mathrm{C}$ \\
$L T P$ & Local thermal perception & $P$ & significances \\
\hline
\end{tabular}




\begin{tabular}{|llll|}
\hline$T_{a}$ & Ambient temperature, ${ }^{\circ} \mathrm{C}$ & $R$ & Correlation coefficient \\
$T_{g}$ & Black-bulb temperature, ${ }^{\circ} \mathrm{C}$ & $\mathrm{df}$ & degree of freedom \\
$R H$ & Relative humidity, $\%$ & $a_{1}$ & Weight coefficient of head \\
$V_{a}$ & Air velocity, $\mathrm{m} / \mathrm{s}$ & $a_{2}$ & Weight coefficient of upper body \\
$A$ & Body surface area, $\mathrm{m}^{2}$ & $a_{3}$ & Weight coefficient of lower body \\
$W$ & Weight, $\mathrm{kg}$ & $\Delta T$ & Temperature difference, ${ }^{\circ} \mathrm{C}$ \\
$h$ & Height, $\mathrm{m}$ & & \\
\hline
\end{tabular}

\section{Introduction}

According to Alhorr et al. [1], people spend 80 to $90 \%$ of their life indoors. Therefore, by technology and living standards development, human beings have a high level of comfort requirement in residential buildings, which causes expansion of building energy consumption. On the contrary, since an energy issue turned into a severe problem, people are forced to seek an 'air-conditioning control' approach, which saves energy and additionally meets the thermal comfort and health requirement. Personal ventilation (PV) was developed and reported [2] as an efficient way to counterbalance the effect. Each occupant is provided with individual control of the supplied personalized flow (flow rate, direction) to achieve the preferred environment by PV system [3]. PV system makes it possible to achieve high air quality in breathing zone, thermal comfort preference and lower energy consumption in buildings. It has always been installed at workstations and provided clean air close to each occupant's breathing zone and improved inhaled air quality $[4,5]$. Measurements demonstrated that properly designed PV systems could provide up to $100 \%$ clean air for inhalation $[4,6]$. The cooling effect of local body adjustment by PV use can also achieve occupant thermal comfort. Zhang [7] showed that upper body segments, such as back and chest, have a dominant impact on the overall sensation during cooling. Zhang and Zhao [8] reported that face cooling could improve thermal acceptability and the upper boundary of the acceptable room temperature range could be shifted from $26^{\circ} \mathrm{C}$ to $35^{\circ} \mathrm{C}$, when face cooling is provided. Similar findings were also reported by Ghaddar et al. [9] and Melikov et al. [2]. Additionally, another major advantage of PV system is its ability to reduce the energy consumption. The estimated energy conservation varied between 4 and $51 \%$ when the cooling set point was increased by $2.5-6{ }^{\circ} \mathrm{C}$ [10]. Temperature dead-band extension to $18-30{ }^{\circ} \mathrm{C}$ by adopting a combined use of personalized heating and cooling, can lead to annual energy savings of approximately 40\% [11]. The key to PV combining local cooling with lower energy use is to increase air movement by adopting local airflow. The standards ASHRAE 55 [12], ISO 7730 [13] and EN 15251 [14] allow elevated air speed to be used to increase the maximum operative temperature for acceptability. Maula et al. 
[15] suggested that providing local cooling with an air jet supply of $0.8 \mathrm{~m} / \mathrm{s}$, might improve both whole body and local thermal comfort at $29.5{ }^{\circ} \mathrm{C}$. However, PV may cause unwanted local cooling of an occupant's body. Thus, to promote the development and application of PV system in building and vehicle, it is of great significance, the establishment of a suitable prediction model that can simulate PV system by analysis of the local thermal sensation impacts on the overall thermal sensation.

Making sure the weight which each local area affects the overall, is the most critical point. In 1992, Ingersoll et al. [16], proposed that the Predicted Mean Vote (PMV) could be defined by using a weight coefficient by part respective area. During car compartment heat environmental studies, Hagino and Hara [17] compared the overall thermal sensation votes to local parts of the thermal sensation votes and obtained the average thermal sensation by area weight coefficient. The adoption of stepwise regression analysis method led to the relationship between the overall and the local thermal sensation. In 2003, by studying the local exposure of 19 body portions, Zhang [7] found that there were differences between various parts of the local and the overall thermal sensation. Chest (including chest and abdomen), back (including the upper back and lower back) and buttock had larger weight coefficient. On the contrary, hands and feet presented lower weight coefficient. In an individual study, Li [18] indicated that the weight coefficient of head and neck were the maximum. Less important but significant was the upper body (including the chest and abdomen), while lower body was of minimal importance. Arens et al. [19] exhibited that in cold environment, some body parts (back, chest and pelvis) mainly affected the overall thermal sensation with hands and feet having insignificant impacts. Based on the desktop task air conditioning experiments, Duanmu et al. [20], found that human thermal sensation was the closest to the sensation of the upper body. The effect on the overall thermal sensation of the head presented the second highest value. The effect of lower body was minimal. In the study on local thermal exposure effects on human thermal reaction, Zhang [21], developed the overall thermal sensation prediction model by adopting influence factor analysis method. According to that the weight coefficient of the face, chest, back and lower body on the overall thermal sensation are $0.21,0.24,0.25$ and 0.30 respectively. Furthermore, Sumee et al. [22], studied the relationship of passenger`s local and overall thermal comfort, by using a questionnaire simulating the flight conditions. As reported, a) in cold environment, the upper and lower body determined the main impact on thermal comfort; b) in a hot environment, the head has the strongest influence on overall thermal comfort. Jin [23], investigated human body local thermal sensation, the local thermal acceptability, the overall thermal sensation, the overall thermal acceptability and the overall thermal comfort and calculated weight coefficient of local 
part, by principal component regression method as follows: head, front chest, back, arm, hand, leg and feet weight: $0.20,0.15,0.16,0.13,0.13,0.13$ and 0.1 respectively. Through the analysis of the survey data, a prediction model of overall and local thermal sensation in different conditions was developed.

As mentioned in the above studies, it can be concluded that due to certain variation in experimental conditions, there is a significant distinction in various parts of the body weight coefficient in the prediction model of the local and overall thermal sensations. Also, the studies above almost exclude physiological characteristics in their experiments. More so, the aboveused models lacked consideration on the cooling orientation of the human body. To this end, the current study sets to bridge some of the existing gaps. Using questionnaire, the study investigates the changes in local and overall thermal sensations. Furthermore, the study establishes a prediction thermal sensation model concerning the overall thermal sensation and the head, torso and lower body. The model considers a) the weight coefficient of human body skin temperature, b) warm and cold receptor density distribution and c) the actual application of regulatory region. The developed model is critical to guide the design and installation of the personal ventilation system. With the remarkable reduction in energy consumption of air conditioning system, the environment under PV can provide human thermal comfort requirements through regulation of strategic parts of the human body.

\section{Materials and Methods}

\subsection{Experimental system}

The experiments were carried out in a climate control chamber in Chongqing University in Chongqing, China. Its volume was $30 \mathrm{~m}^{3}(4 \times 3 \times 2.5 \mathrm{~m}, \mathrm{~L} \times \mathrm{W} \times \mathrm{H})$. To obtain the precise thermal environment and reduce other effects, the building envelope of the chamber is made of steel plate with polystyrene foam. The control system offers several airflow formats, including side air supply and side return, top-supply and bottom-return air supply, top diffuser supply. The air supplied to the chamber ambient was a mixture of fresh and recirculated air. In the chamber, the air temperature, relative humidity, and velocity were automatically controlled, and the accuracy of control systems was $\pm 0.2{ }^{\circ} \mathrm{C}, \pm 5 \%$ and $\pm 0.02 \mathrm{~m} / \mathrm{s}$ as presented in Fig. 1. An official desk, some publications and a laptop were fixed in the chamber to create an authentic office atmosphere.

Air was supplied through the perforated side wall and returned into the chamber through the perforated opposite side wall (see Fig.1). The scope of this experimental design was to 
achieve uniform thermal environmental parameters in the occupied zone. In the chamber, the chamber air temperature $\left(T_{a}\right)$, black-bulb temperature $\left(T_{g}\right)$, relative humidity $(R H)$ and air velocity $\left(V_{a}\right)$ were measured. To record relative measurements, a comprehensive thermal environment acquisition system was fixed at the height of $1.1 \mathrm{~m}$ from the floor. Sensors used in the thermal environment acquisition system were a Psychrometer sensor, a Radiant temperature sensor, a Psychrometer sensor (relative humidity) and a Hot wire anemometer sensor. Accuracy was $\pm 0.1^{\circ} \mathrm{C}, \pm 0.15^{\circ} \mathrm{C}, \pm 1 \%$ (40\% 70\%), $\pm 0.5 \%$ (70\% $\left.98 \%\right), \pm 0.04 \mathrm{~m} / \mathrm{s}$ respectively. The Italy Richter LST thermal comfort instrument) was used as a monitor and data acquisition system.

\subsection{Experimental Conditions}

Twenty subjects participated in the experiment, consisting of healthy college students. The number of the male students and the female students was identical. Each subject participated five times in experiments. During every experiment, subjects were asked to wear a uniform: short sleeve t-shirt cotton, cotton shorts, and slippers. In this investigation, the clothing insulation is the total insulation. In the ASHRAE Handbook [24], it reported that the most accurate ways to determine clothing insulation are (1) measurements on heated mannequins [25, 26], and (2) measurements on active subjects [27]. However, clothing insulation cannot be measured for most routing engineering applications. The ASHRAE Handbook affords a list clothing insulation of individual garments commonly worn. The insulation of an ensemble is estimated from the individual values using a summation formula [26], as follows:

$$
I_{c l}=0.835 \sum_{i} I_{c l u, i}+0.161
$$

While $I_{c l u, i}$ is the effective insulation of garment $i$, and $I_{c l}$, as before, is the insulation for the entire ensemble. A simpler and nearly as accurate summation formula is as follows [28]:

$$
I_{c l}=\sum_{i} I_{c l u, i}
$$

Both Equations (1) and (2) give insulation with acceptable accuracy for typical indoor clothing. Thus, in this investigation, the total clothing insulation was calculated by Equation (2).

The clothing insulation was approximately 0.32 clo (including chair thermal resistance 0.05 clo) Error! Reference source not found.. Every subject filled in the basic information before the experiment, including name, age, gender, height, weight, and health condition. Information of the participants was presented in Table 1.

According to the ASHRAE 55-2013 [12] requirements of the building, the air velocity around 
the human body was regulated approximately $0 \sim 0.35 \mathrm{~m} / \mathrm{s}$. During the experimental procedure in building in Chongqing, the indoor air temperature was ranged from $25^{\circ} \mathrm{C}$ to $29^{\circ} \mathrm{C}$ [30]. Therefore, the ambient temperature set point was set from $26{ }^{\circ} \mathrm{C}$ to $28{ }^{\circ} \mathrm{C}$, the relative air humidity was set in three levels of $40 \%, 60 \%$ and $80 \%$ with the air velocity fixed at about $0.1 \mathrm{~m} / \mathrm{s}$. The mean radiant temperature $\left(T_{m r t}\right)$ for forced convection was calculated from the measured $T_{g}, V_{a}, T_{a}$, globe emissivity ( $\varepsilon_{g}$, assumed to be 0.95 ) and diameter (D, approximately $110 \mathrm{~mm})[31]$ :

$$
T_{m r t}=\left\{\left(T_{g}+273\right)^{4}+\left[\frac{\left(1.1 \times 10^{8} \times V_{a}^{0.6}\right)}{\left(\varepsilon_{g} \times D^{0.4}\right)}\right] \times\left(T_{g}-T_{a}\right)\right\}^{1 / 4}-273
$$

The operative temperature $\left(T_{o p}\right)$, which considers the impact of air temperature, mean radiation temperature and air velocity on thermal comfort, is calculated by the following equation [12]:

$T_{o p}=\left(T_{a}+T_{m r t}\right) / 2$

Table 2 shows the experimental conditions in the study. During the experiment, subjects were allowed to deal with vocations such as reading books and playing electronics but need to maintain 1.0 met (metabolic rate).

\subsection{Experimental Procedure}

Each section was divided into two parts, lasting for 1.5 hours. Before the experiment, the thermal environmental parameters on the laboratory were set up, to meet the proposed experimental conditions. Preparatory work was done to subjects, including appropriate clothing, body thermocouple installation, and information provision to ensure that the steps of the experiment are clear. After that, subjects entered the laboratory for 30 minutes in a stationary position and then the experiment began with 1-hour duration. The subjects should fill in questionnaire every 10 minutes during the experiment. This included nine parts of the human thermal sensation. Table 3 presents the voting scale used in the subjective experiments. Subjects were allowed to sit in the chair while reading a book or to use the computer during the whole experiment procedure.

\subsection{Determination of the steady-state for calculation}

In this investigation, the experiment consists of two parts. The first part is the steady 
experimental stage, lasting 30 minutes. The subjects were required to seat in a station the experimental cabin and answered the questionnaire every 10 minutes. After the first 30 minutes, the subjects were also required to respond to the questionnaire every 10 minutes. This section lasted 1 hour. Thus, the whole experiment procedure continued for one and half hours. To determine the point of the steady time in the experiment, many previous investigations were analyzed. Based on the experimental investigation, in the steady thermal environment, Fanger [32] reported the human thermal sensation changed against time with significant difference ( $p$ value $<0.05$ ) in the first 15 minutes. However, after the first 15 minutes, the variation of the thermal sensation vote is non-significant ( $p$-value $>0.05$ ). Goto et al. [33] examined sensation and comfort responses during and after three activity levels. They found that after 15 minutes of the up-step and down-step activities, the sensation and comfort had reached steady-state values. Nagano et al. [34] showed that people's mean skin temperature, sensation, and comfort reaches stable conditions in 20 minutes after a step-change move from a hot a neutral environment. Zhang [7] found that the subject's sensation and comfort votes stabilized after about half an hour. Once sensation stabilizes, it varies only slightly. By the experimental conditions, the experimental procedure was very similar to the Zhang' experimental investigation. Thus, during the experimental procedure, after the first 30 minutes, the human body responses stabilized (see Fig.2). Thus, in one hour after the first 30 minutes, thermal sensation votes were used to calculate the mean thermal sensation values.

\section{Results}

\subsection{Changes in local thermal sensation and the overall thermal sensation}

Fig. 3 illustrates the variation of local and overall thermal sensations under different conditions. It can be concluded that for each body part, local and overall thermal sensation votes were below 0 when the air temperature was $26^{\circ} \mathrm{C}$. Additionally, the thermal sensation was higher than 0 in $28^{\circ} \mathrm{C}$ (much higher than that of $26^{\circ} \mathrm{C}$ ). The increase of thermal sensation vote can be explained since air temperature was higher and heat exchange between the human body and the thermal environment reduced, while heat storage capacity increased. This was confirmed by the body heat balance equation [35]. By comparison, to all local thermal sensation, the local thermal sensation of head, chest, back, and hand was higher while that of arms and legs was low. Especially while the lower leg maintained low ambient temperature conditions, the local thermal sensation of the head was pronounced. The reason for that is that the head is 
consisted to be the radiator of the body for distributing more abundant blood vessel [36]. The chest and back collect the core of the body heat. Thus their temperature and thermal sensation were both higher (see Fig. 4). Some investigations [21, 37] found, in the narrow range, there was an excellent linear relationship between overall thermal sensation and mean skin temperature. Thus, it has been applied to evaluate the thermal stress or comfort [37-40]. The body heat core was located in the trunk of the body, including the chest, back, and other local parts. The core temperature always kept near $37{ }^{\circ} \mathrm{C}$ [41]. Thus, the local skin temperatures of chest and back were higher than another local part (see Fig 4.). Based on the above analysis, the local sensations of the chest and back were always greater than other local parts.

Besides, the arms and legs were far enough from the body heat production center; their skin temperature was lower than other regions, especially the lower leg, shown in Fig. 4 Therefore, the thermal sensation was lower. From Fig. 4, it was easy to find out that the skin temperatures of head, chest, and back were much higher than other parts. The maximum skin temperature of the local part was from the chest. It was $34.65^{\circ}$ and $34.95^{\circ} \mathrm{C}$ respectively, at $26^{\circ} \mathrm{C}$ and $28^{\circ} \mathrm{C}$ conditions. However, skin temperature of lower leg was the minimum. It was $31.13{ }^{\circ} \mathrm{C}$ and $31.87{ }^{\circ} \mathrm{C}$ respectively, at $26{ }^{\circ} \mathrm{C}$ and $28{ }^{\circ} \mathrm{C}$ conditions. The skin temperature difference between chest and lower leg was nearly $3{ }^{\circ} \mathrm{C}$. The mean skin temperature located in the middle, $33.29^{\circ} \mathrm{C}$ and $33.93{ }^{\circ} \mathrm{C}$ respectively.

To determine the variation rate of the local thermal sensation, the variations of local and overall thermal sensations with running time under the condition of $28{ }^{\circ} \mathrm{C}$ with $60 \%$ relative humidity were shown in Fig.5. All variations of the thermal sensation were similar. In the beginning, all the thermal sensations, including local thermal sensation and overall thermal sensation, were the highest. Moreover, then, they dramatically decreased with the running time. Most of them stabilized after the first 30 minutes. The variations of both chest and back thermal sensation were more significant than another local part (see Fig.5). Therefore, effect sensitivities of the chest and back were more significant in overall thermal sensation, which proved the results shown in Fig. 4 and $\mathbf{5}$.

By considering $26^{\circ} \mathrm{C}$ as an example, it is apparent that the effect of the relative humidity on human thermal sensation was very weak under the conditions of the same air temperature with different relative humidity. The local and overall thermal sensations in high relative humidity were more intense compared to the low relative humidity, but not significant. In $26^{\circ} \mathrm{C}$ 
condition, by comparing the local and overall thermal sensations in two different levels of relative humidity, the average difference was 0.049 . In $28^{\circ} \mathrm{C}$, the difference reduced to 0.032 . The differences were not significant. Based on the above analysis, authors ignored the effect of air relative humidity on human local and overall thermal sensations. Thus, by the experimental data of $26^{\circ} \mathrm{C}$ and $28^{\circ} \mathrm{C}$ conditions, the prediction model was analyzed.

\subsection{Comparison of Local and overall thermal sensations}

In Fig. 6, a variation of the local thermal sensation vote based on overall thermal sensation is illustrated. Thermal sensations of the head, chest back and hand were higher than overall, which denoted that these body parts felt warmer than overall. The basis for that can be as follows: when persons were stationary, the heat production of head accounted for $16 \%$ of the whole body and the internal organs for 56\% [42], considering the two primary heat sources. The chest and back were both close to internal organs. The head and specifically the face is rich in capillaries, which is considered as a radiator of the complete human body [36]. The pores of the head usually remain wide. Moreover, another reason is lack of vasoconstrictor nerves in the scalp blood vessels, covering the majority area of the human face, which always kept outstretched [43]. Furthermore, the blood supply of head accounted for $14 \%$ of all cardiac output. Thus, skin temperatures of the head, chest, and back were higher, as well as the thermal sensation. Additionally, consisting the extremity of the body, hands are rich in nerve endings, as well as hot and cold sensors, including rich and dense subcutaneous blood circulation and microcirculation. Hand back temperature was similar to body temperature, and palm temperature was slightly higher thus, the hand thermal sensation was greater than overall.

The mean local thermal sensation of arm, thigh and lower leg was lower than overall. The lower leg thermal sensation was particularly colder than overall. The subjects' clothing included short-sleeved T-shirt and shorts, according to ordinary people's attire code during summer [44]. Thus, the majority of subject's arms and legs were exposed in the ambient environment, exchanging heat directly with air. Furthermore, these local body parts were beyond the body core [45], which caused a lower skin temperature. Thus, the thermal sensation was lower. Also, one particular local body part was a foot, which was colder than overall, in an environment temperature of $26^{\circ} \mathrm{C}$, but warmer in $28^{\circ} \mathrm{C}$.

\subsection{Relationship between Local and Overall Thermal Sensations}

Fig. 7 explains the relationship between local and mean overall thermal sensation in 
separation. All of eight body parts were classified into two groups. The first one contained head, chest, back and hands (all of which gain higher votes of thermal sensation) and the other one included the rest body parts. Fig. 7(1) clarifies the relationship between mean local and overall thermal sensations of head, chest, back, and hand. Fig. 7(2) points out the relationship of the arm, thigh, lower leg, and foot. In Fig. 7(1), the mean thermal sensation was approximately concentrated, and the regression lines of each body part are relatively close to each other. This is due to the limited distance of these four body parts to the body core, which leads to the close relationship to the local and overall thermal sensations. In Fig. 7(2), mean thermal sensation of the arm, thigh, lower leg, and foot were more dispersed, likewise their regression lines and mean thermal sensation were lower. The regression slopes in Fig 7(2), were typically greater compared to those in Fig 7(1). Nevertheless, all the linear relationships were statistically significant in considering the eight body parts. The results of correlation and significance analysis are introduced in Table 4. All correlation coefficients $(r)$ were higher than 0 , which indicated a positive correlation. Furthermore, all p-value was lower than 0.05 , which indicated a significant correlation. Therefore, the local thermal sensation was linearly correlated to the overall thermal sensation. Also, the correlation coefficients of chest and back presented the higher values as shown in Table 4. An explanation for that would be the close distance of chest and back to the body core, which kept skin temperature of them close to core temperature values.

\section{Establishment of the model}

The overall thermal sensation can be considered as the integration of every local thermal sensation signal through brain control, which leads to a strong relationship between overall and local thermal sensation. Authors adopted the weight coefficient in the mean skin temperature calculation formula, according to Gagge and Nishi's 8-point method [46] (Equation 5) and Hardy and Dubio's [47] 7-point method (Equation 6) as follows:

$$
\begin{aligned}
& \text { MTS } S_{\text {gagge/Nishi }(8 \text { point })}=0.07 t_{\text {head }}+0.175 t_{\text {chest }}+0.175 t_{\text {back }}+0.07 t_{\text {upper } \text { arm }}+0.07 t_{\text {lower arm }}+0.05 t_{\text {hand }} \\
& +0.19 t_{\text {thigh }}+0.2 t_{\text {lower leg }} \\
& M T S_{\text {Hardy/Dubio( } 7 \text { points })}=0.07 t_{\text {head }}+0.35 t_{\text {abdomen }}+0.14 t_{\text {lower arm }}+0.05 t_{\text {hand }}+0.19 t_{\text {thigh }}+0.13 t_{\text {lower }} \\
& \text { leg }+0.07 t_{\text {foot }}
\end{aligned}
$$

Those methods had been strictly validated and were used to calculate the mean skin temperature. By a combination of Eqs. (5) moreover, (6), the eight body parts' weight coefficients were obtained, as shown in Table 5.

In the early $20^{\text {th }}$ century, many investigations found out the warm receptor and cold 
receptor distributed in the human skin [48-51]. When the thermal environment stimulated the non-uniform distributed skin temperature receptors, human body felt hot or cold. In 1930, Bazett et al. [50, 51] demonstrated that cold receptors situated in the germinal layer 0.15$0.17 \mathrm{~mm}$ under the skin surface in addition to the warm receptors fixed in $0.3-0.6 \mathrm{~mm}$ under the skin surface. By many experimental investigations. The receptor density of local body parts was described and summarized in Table 6.

Based on the statistical density of cold receptors' distribution in Table 6, the average density of cold receptors distribution of local body parts was calculated and summarized in Table 7.

Based on above analysis, the whole body was divided into three main sections, including head, upper body, and lower body. The combination of different body part's weight coefficient in calculating mean skin temperature and the density of cold receptors, the weight coefficient of local parts in upper or lower body was calculated by the Equation (7), as follow.

$a_{u i}=\frac{A \rho_{i} * a_{s k i}}{\sum_{i} A \rho_{i} * a_{s k i}}$

$a_{u i}$ - the weight coefficient of local parts in upper body or lower body.

$A$ - the area of the human skin surface, $\mathrm{m}^{2}$;

$\rho_{i}$ - the density of cold receptors, $\mathrm{cm}^{2}$;

$a_{s k i}$ - the weight coefficient of local parts in area skin surface.

While calculating the weight coefficient of local parts in the upper body, $i$ means chest, back, arm, or hand. Whist calculating the weight coefficient of local parts in lower body, $i$ means thigh, lower leg, or foot. The calculating results were presented in Table 7. The calculation procedure is illustrated in Fig. 8.

According to the weight coefficient in Table 8, the actual data were classified, and the voting value of head, upper and lower body's thermal sensation was calculated in 5 different working conditions as shown in Table 9.

The mean overall thermal sensation and these three body parts' local average thermal sensation share the following formula:

$\mathrm{MTSV}=a_{1} T S V_{\text {head }}+a_{2} T S V_{\text {upper }}+a_{3} T S V_{\text {lower }}$

$a_{1}$ - weight coefficient of head, $T S V_{\text {head }}$ - thermal sensation of head;

$a_{2}$ - weight coefficient of upper body, $T S V_{\text {upper- }}$ thermal sensation of upper body;

$a_{3^{-}}$- weight coefficient of lower body, $T S V_{\text {lower }}$ - thermal sensation of lower body;

Considering all data in Table 8 and the equation $a_{1}+a_{2}+a_{3}=1$, the weight coefficients of the three body parts were determined as displayed in the following Table 10.

The entire process of this model establishment was described in Fig. 8. 
The prediction results were calculated by Equation (8). Based on the experimental data, the MTSV of the model and experiments were compared, shown in Fig 9. There was a strong relationship between the model predictive results and experimental results with the high $\mathrm{R}^{2}$ (0.94). This indicated that the MTSV prediction model could be applied to evaluate the thermal environment.

\section{Discussion}

\subsection{The variation of thermal sensation with relative humidity.}

Relative humidity is one of the most important factors to affect thermal comfort. However, in the famous Standards, they give the general guidance. In the ASHRAE Standard 55-2013 [12], while keeping the indoor thermal environment in a thermal comfort zone, the air conditioning system shall be able to maintain a humidity ratio at or below 0.012 . It does not specify a minimum humidity level. In Chinese indoor air quality standard (GB18883-2002)[52], the relative humidity of $40 \%$ to $80 \%$ was required in HVAC building in summer. Thus, the effects of relative humidity on thermal sensation in the acceptable thermal comfort zone need to be analyzed. Based on the results shown the Fig 3, the variations of the thermal sensation with different relative humidity levels were only slight. To further determine the differences between the two groups of experimental conditions, we analyzed the results by paired samples $t$-test [53]. Results were as presented in Table 11. All of the p-value (significance) were larger than 0.05 . Therefore, there was no significant difference between the two experimental conditions, which indicated that the air temperature of $26^{\circ} \mathrm{C}$, relative humidity of $40 \%, 60 \%$, and $80 \%$ provided insignificant effects on human thermal sensation. The results of the differences between two different levels of relative humidity in $28^{\circ} \mathrm{C}$ were similar to the $26^{\circ} \mathrm{C}$ and identical to the findings of Fanger Error! Reference source not found., Xu et al. Error! Reference source not found. and Hayakawa et al. Error! Reference source not found.. As early as 1973, Andersen [56] indicated that when the relative humidity varied in the range of $70 \%$ to $10 \%$, thermal sensation remains unaffected. In the Chinese Standard, the GB 50736 [57] specifies that in the Rank of the thermal comfort zone, the relative humidity should be in the range of $40 \%$ to $60 \%$. In the II Rank of the thermal comfort zone, the relative humidity does not exceed $70 \%$. Based on this investigation result, we conclude that there are no significant effects of the relative humidity of $40 \%, 60 \%$ and $80 \%$ in the two different air temperature levels $\left(26^{\circ} \mathrm{C}\right.$ and $28^{\circ} \mathrm{C}$ ), which support the regulation of GB 50736 in another side.

\subsection{The effects of the local parts on the prediction model}


It was pronounced that the upper body's weight coefficient was the highest, the weight coefficient of head presented the second largest value, and that of lower body was the minimum. The dominant interpretation could be that the upper body consisting of chest, backside, upper arm, lower arm, hands chest, backside and upper arms approach human body's heat producing center. Their skin temperatures were more close to core temperature than those of other local parts, which results in a strong influence on overall thermal sensation. Furthermore, hands constitute the end of the human body and include plenty of nerve endings and temperature receptors, which contributes significantly to the overall thermal sensation. The lower body was far enough from the human body core. Thus the effect on the total body was insignificant. The results were rather similar to previous studies [17-22]. Zhang [7] demonstrated that chest, back and buttocks, which were included in the upper body, had considerable weight effect. Arens et al. [19], considered that back, chest, and pelvis had the most significant effect on overall thermal sensation under cold conditions. Duanmu et al. [20] reported that the overall thermal sensation is almost similar to upper body's thermal sensation. Zhang [21] also concluded that the chest and back presented strong effect on the overall thermal sensation, which was 0.24 and 0.25 by adopting the method of influencing factors. Jin [22] demonstrated a similar result as well. To summarize, the models of overall and local thermal sensation were evaluated as presented in Table 11.

By model comparison, it can be concluded that the head was included in the majority of the models and head thermal sensation had a significant influence on overall thermal sensation. Some of the studies indicated that it was an efficient way to cool the head in personal ventilation. However, when the head was exposed in an environment with high air velocity, people would have obvious draft sensation [58], and symptom such as dizziness and headache ensued. Furthermore, few models can be particularly grouped into two types: the first category subdivides the body into many parts, while the second one divides the body into three sections: head, upper body, and lower body. Dividing the body into three sections was based on the existing buildings, transportation, and additional personal air supply adjustment equipment. In practical application, the stimulation part was to the range of a body, not a single body part. Considering the particularity of personal ventilation, as a nozzle jet, the body was divided into three parts: the head, upper body, and lower body. It was concluded according to the weight coefficient of models that the upper body was the most significant body part, which indicates that cooling the upper body is critical for the overall thermal comfort for PV use. By above research results comparison, most of the research models were obtained by simple regression analysis. Thus some results cannot be consistent with the actual physical meaning, such as a 


\section{Energy and Buildings}

Volume 158, 1 January 2018, Pages 1286-1295

negative number of the regression coefficient of a certain body part. In this approach, a comprehensive analysis of the weight coefficient of the mean skin temperature, the density distribution of heat sensors and the actual values of human thermal sensation vote were conducted. Comparing the weight coefficient of the average skin temperature and weight coefficient of this model, it is easy to find that there are significant differences in both equations of mean skin temperature and thermal sensation prediction models. The weight coefficient of the head was 0.07 in Equation 1. However, in this model, the weight coefficient of the head was 0.22 higher than 0.07 . The primary reason was that the area size of the head was minimal. Nevertheless, the density of cold receptors in the head skin was higher than other local body parts, which lead the head weight coefficient of this model to be greater than that of mean skin temperature. The lower body weight coefficient in this model was lower than that of mean skin temperature. The area size of the lower body part is large. However, the density of cold receptors of this body part was very low, which caused the lower body part weight coefficient of the prediction model to be lower than other parts. Considering effects of skin temperature, the density of cold receptor, and actual response, the model of this study constitutes a benefit for application of PV systems.

\section{Conclusion}

To develop prediction thermal comfort model for evaluation PV system, a series of experimental conditions were examined in an artificial climate chamber. By adopting the method of questionnaire inquiry, local thermal sensation on overall thermal sensation was analyzed by a combination of the weight coefficient of the average skin temperature, the density distribution of heat sensors and the experimental data. Thus, the following conclusions were pronounced:

1) In a stable thermal environment, there were certain differences between each local and overall thermal sensations. The mean thermal sensation of the head, chest, back, and hand was significantly higher than the overall thermal sensation. On the contrary, a thermal sensation of arms, thighs and lower legs was lower. Specifically, the lower leg was cooler than the whole body.

2) A clear linear relationship between local and overall thermal sensations was presented. Among body parts, the chest and back had the largest linear correlation with the whole body. Also, the thermal sensation of four parts, including head, chest, back, and hand were quite concentrated without significant differences. However, the thermal sensation of arms, thighs, legs, and feet were relatively scattered, and each of them was less than overall thermal 
sensation, which regression line was also approximately scattered.

3) Considering the scope of actual regulation, the human body was divided into three parts: head, upper body, and lower body. The model adopted indicated the relationship of the thermal sensation between the three parts and body as a total. The weight coefficients of these three parts were calculated as $0.21,0.60$ and 0.19 respectively, which demonstrate that the upper body had the most critical effect on overall thermal sensation.

\section{Acknowledgments}

The authors are grateful for the support of: The Major State Basic Research Development Program of China (973 Program) (Project No. 2012CB720100) and to the International Research Centre for Low-carbon and Green Buildings, Chongqing University. Also, appreciated Dr. Daniel Mmereki help, in English language check and the volunteers joined the experiment.

\section{Reference}

[1]. Y. Alhorr, M. Arif, M. Katafygiotou, A. Mazroei, A. Kaushik, E. Elsarrag. Impact of indoor environmental quality on occupant well-being and comfort: A review of the literature. International Journal of Sustainable Built Environment. 5 (1) (2016) 1-11.

[2]. A.K. Melikov. Personalized ventilation. Indoor Air. 14 (suppl. 7) (2004) 157-167.

[3]. A.K. Melikov, T. Ivanova, G. Stefanova. Seat headrest-incorporated personalized ventilation: Thermal comfort and inhaled air quality. Building and Environment. 47 (2012) 100108.

[4]. A.K. Melikov, R. Cermak, M. Mayer. Personalized ventilation: evaluation of different air terminal devices. Energy and Buildings. 34 (8) (2002) 829-36.

[5]. J. Kaczmarczyk, A. Melikov, P.O. Fanger. Human response to personalized and mixing ventilation. Indoor Air. 14(Suppl. 8) (2004) 1-13.

[6]. Z. Bolashikov, L. Nikolaev, A. Melikov, J. Kaczmarczyk, P.O. Fanger. New air terminal devices with high efficiency for personalized ventilation application. In: Proceedings of healthy buildings. Singapore. 2 (2003) 850-55.

[7]. H. Zhang. Human thermal sensation and comfort in transient and non-uniform thermal environments. PhD Thesis. University of California. Berkeley. 2003.

[8]. Y. Zhang, R. Zhao. Effect of local exposure on human responses. Building and Environment. 42 (2007) 2737-2745.

[9]. N. Ghaddar, K. Ghali, S. Chehaitly. Assessing thermal comfort of active people in transitional spaces in presence of air movement. Energy and Buildings. 43 (10) (2011) 28322842.

[10]. S. Schiavon, A.K. Melikov, C. Sekhar. Energy analysis of the personalized ventilation system in hot and humidclimates. Energy and Buildings. 42(2010) 699-707. 
[11]. M. Veselý, W. Zeiler. Personalized conditioning and its impact on thermal comfort and energy performance - A review, Renewable and Sustainable Energy Reviews. 34 (2014) 401-408.

[12]. ASHRAE, ANSI/ASHRAE Standard 55-2013: "Thermal Environment Conditions for Human Occupancy". Atlanta, GA, American Society of Heating, Ventilating and AirConditioning Engineers, Inc., 2014.

[13]. ISO 7730, Ergonomics of the Thermal Environment. Analytical Determination and Interpretation of Thermal Comfort Using Calculation of the PMV and PPD Indices and Local Thermal Comfort Criteria, International Organization for Standardization, Gen_eve, 2005.

[14]. CEN (European Committee for Standardization), EN 15251, Criteria for the Indoor Environment Including Thermal, Indoor Air Quality, Light and Noise, European Committee for Standardization, Brussels, Belgium, 2007.

[15]. H. Maula, V. Hongisto, H. Koskela, A. Haapakangas. The effect of cooling jet on work performance and comfort in warm office environment. Building and Environment. 104(2016) 13-20.

[16]. J.G. Ingersoll, T.G. Kalman, L.M. Maxwell. Automobile passenger compartment thermal comfort model-part II: human thermal comfort calculation. SAE Technical Paper Series, NO 920266, (1992) 1-11.

[17]. M. Hagino, J. Hara. Development of a method for predicting comfortable airflow in the passenger compartment. SAE Technical Paper Series, NO 922131, (1992) 1-10.

[18]. J. Li. Characteristic of individual air supply and research on Human thermal response. Master dissertation of Tsinghua University. 2004. (In Chinese)

[19]. E. Arens, H. Zhang, C. Huizenga. Partial-and whole-body thermal sensation and comfort-Part II: Non-uniform Environmental Conditions. Journal of Thermal Biology. 31(2006) 60-66.

[20]. L. Duanmu, H. Shu, Z. Wang, W. Li, S. Shen, Experimental Research on Human Thermal Sensation under Diverse Indoor Environment Parameters, Journal of Shenyang Jianzhu University. 23 (1) (2007) 117-121. (In Chinese)

[21]. Y.Zhang. Effect of local exposure on human responses. Ph.d. Dissertation of Tsinghua University. 2005.

[22]. S. Park, R.T. Hellwig, G. Grün, A. Holm. Local and overall thermal comfort in an aircraft cabin and their interrelations. Building and Environment. 46 (2011) 1056-1064.

[23]. Q. Jin. Study on Thermal Sensation during Step-change in Non-uniform Thermal Environment. Ph.D. Daling university of technology. 2012.

[24]. ASHRAE, ASHRAE Handbook- Fundamentals, Chapter 9, Thermal Comfort, 2013.

[25]. McCullough, E.A. and B.W. Jones. 1984. A comprehensive data base for estimating clothing insulation. IER Technical Report 84-01, Institute for

Environmental Research, Kansas State University, Manhattan. ASHRAE Research Project RP411, Final Report.

[26]. Olesen, B.W. and R. Nielsen. 1983. Thermal insulation of clothing measured on a moveable manikin and on human subjects. Technical University of Denmark, Lyngby.

[27]. Nishi, Y., R.R. Gonzalez, and A.P. Gagge. 1975. Direct measurement of clothing heat transfer properties during sensible and insensible heat exchange with thermal environment. 
ASHRAE Transactions 81(2):183.

[28]. Olesen, B.W. 1985. A new and simpler method for estimating the thermal insulation of a clothing ensemble. ASHRAE Transactions 91(2).

[29]. T.T. Chow, K.F. Fong, B. Givoni, Z. Lin, A.L.S. Chan. Thermal sensation of Hong Kong people with increased air speed, temperature and humidity in air-conditioned environment. Building and Environment. 45 (2010) 2177-2183.

[30]. H. Liu, Thermal comfort indoor dynamic environment in Chongqing. PH.D. Chongqing University. 2009.(In Chinese)

[31]. ISO7726-2001: Thermal Environments specifications relating to appliances and Methods for Measuring Physical Characteristics of the Environment. Geneva, International Standard Organization, 2002.

[32]. P.O. Fanger. Thermal comfort - analysis and application in environment engineering. Copenhagen. Danish Technology Press. 1970.

[33]. Goto, T., J. Toftum, et al. (2002). Thermal Sensation and Comfort with Transient Metabolic Rates. Proceedings of Indoor Air Conference, Monterey, USA, June 30 - July 5.

[34]. Nagano, K., A. Takaki, et al. (2002). Thermal Responses to Temperature Steps in Summer. The 10th International Conference on Environmental Ergonomics, Fukuoka, Japan.

[35]. Y. Zhu. Building Environment. China Architecture \& Building Press. 2010.(In Chinese)

[36]. S.A. Nunneley, R.J. Maldonado. Head and/ or torso cooling during simulated cockpit heat stress. Aviat Space Environ Med. 54 (6) (1983) 496-499

[37]. Wang D, Zhang H, Arens E and Huizenga C. Observations of upper-extremity skin temperature and corresponding overall body thermal sensations and comfort. Build Environ 2007; 42: 3933-3943.

[38]. Choi JH and Loftness V. Investigation of human body skin temperatures as a bio-signal to indicate overall thermal sensations. Build Environ 2012; 58: 258-269.

[39]. Nagano K, Takaki A, Hirakawa $M$ and Tochihara Y. Effects of ambient temperature steps on thermal comfort requirements. Int J Biometeorol 2005; 50: 33-39.

[40]. Yao Y, Lian Z, Liu W and Shen Q. Experimental study on physiological responses and thermal comfort under various ambient temperatures. Physiol Behav 2008; 93: 310-321.

[41]. Yao Tai, Zhao Zhiqi, Zhu Danian, Yang Xiongli, human physiology, People's medical publishing house, 2015

[42]. I. Andersen, G.R. Lundqvis, D.F. Proctor. Human perception of humidity under 4 conditions. Archives of environmental health, 26 (1973) 22-27.

[43]. Y. Ou, The development of overseas water cooled garment equipment, Military Hygiene, 3 (1981) 75-85.

[44]. B.A. Williarns, A. Shizer. Modular liquid-cooled helmet liner for thermal comfort, Aerospace Medicine, 45 (9) (1974) 1030-1036

[45]. Z. Jin. Thermal Adaptation Behavior and Thermal Comfort Zone for Chinese resident. Ph.D. Chongqing university. 2011.

[46]. Gagge AP, Nishi Y (1977) Heat exchange between human skin surface and thermal environment. In: Lee DHK (ed) Handbook of physiology. American Physiological Society, Bethesda, Md pp 69-92 
[47]. Hardy JD, DuBois EF (1938) The technic of measuring radiation and convection. J Nutr 15:461-475

[48]. Y Zhu, Building Environment, China Architecture \& Building Press, 2010

[49]. H. Hensel, Thermo-reception and Temperature, London: Academic Press, 1981.

[50]. C. Bazett and B. McGlon. Experiments on the mechanism of stimulation of end organs for cold. American Journal of Physiology. 93 (1930) 632.

[51]. H.C. Bazett, B. McGlon, R.J. Brocklehurst. The temperature in the tissue which accompanies temperature sensations. Journal of Physiology. 69 (1930) 88-112.

[52]. GB18883-2002

[53]. W. Lu. Statistical Analysis of SPSS. Publishing House of Electronics Industry. Beijing. 2003.

[54]. T. Xu, E. Arens, F. Bauman. "The Effects of High-Level Air Humidity on Subjective Perception of Comfort." Proceedings of the 2nd International Symposium on Heating, Ventilation, and Air Conditioning. Beijing. China. 25-27 (September 1) (1995) 81-91.

[55]. K. Hayakawa, N. Isoda, T. Yanase. Study of the effects of air temperature and humidity on the human body during physical exercise in the summer. Journal of Architecture, Planning, and Environmental Engineering (Transactions of AIJ), (1989) 405.

[56]. I. Andersen, G.R. Lundqvis, D.F. Proctor. Human perception of humidity under 4 conditions. Archives of environmental health, 26 (1973) 22-27.

[57]. GB 50736

[58]. P.O. Fanger, A.K. Melikov, H. Hanzawa, J. Ring. Air turbulence and sensation of draught. Energy and Buildings. 12 (1988) 21-39. 